\title{
Yolanda Oreamuno y el panorama artístico costarricense en Repertorio Americano
}

\author{
Sigrid Solano Moraga \\ Escuela de Literatura y Ciencias del Lenguaje \\ Universidad Nacional, Costa Rica
}

\section{Resumen}

Repertorio americano representó una apertura al diálogo con intelectuales sobre perspectivas artísticas nacionales e internacionales. Entre ellos se contó con la participación de Yolanda Oreamuno, quien, a partir de un conjunto de textos literarios, evaluó el carácter del costarricense hacia el arte, expuso la carencia de crítica hacia los artistas y sus creaciones, y criticó el costumbrismo en las letras. Esta investigación tiene por objetivo estudiar el panorama artístico descrito en los ensayos y narrativa lírica de la autora, publicados en la revista dirigida por Joaquín García Monge, entre ellos: "La vuelta a los lugares comunes" (1939), "El último Max Jiménez ante la indiferencia nacional" (1939), "Protesta contra el folclore" (1943) y "Max Jiménez y los que están” (1947). Los anteriores escritos exponen el carácter transgresor de Oreamuno, su producción crítica y dialógica; además, la imponen como pensadora ruptora de roles sociales.

Palabras claves: literatura costarricense, Yolanda Oreamuno, Repertorio Americano, ensayos

\begin{abstract}
Repertorio Americano represented a dialogue about different perspectives, between national and international intellectuals. Yolanda Oreamuno was one of the important collaborators of this newspaper. She evaluated Costa Rican passivity against the arts, and also the costumbrismo in literature. This research attempt to study the artistic scene described by Oreamuno in her essays and narrative poetry, among them: "La vuelta a los lugares comunes" (1939), "El último Max Jiménez ante la indiferencia nacional" (1939), "Protesta contra el folclore" (1943) y "Max Jiménez y los que están" (1947). Those documents suggest the transgressor role to the system by this female writer, as well as a critical and dialogic literature.
\end{abstract}

Keywords: Costa Rican literature, Repertorio Americano, essays, Yolanda Oreamuno 
$R$ epertorio Americano fue un espacio para la exposición de creaciones artísticas nacionales como internaciones. De ahí que Yolanda Oreamuno expusiera el importante papel de Joaquín García Monge al describirlo como "la única persona que en todo momento a través de tantos años y ante tantas cosas ha mantenido una actitud de ponderación y receptividad" (Oreamuno, 1939: 3). Cuando Oreamuno califica a don Joaquín de ponderado y receptivo no exagera; gracias a este visionario conservamos sendos artículos, por ejemplo 20 escritos de Yolanda Oreamuno, lo cual funciona como ejemplo de su valor al publicar críticas hacia la intelectualidad y el ambiente del momento, así como promover "la actualización del paisaje cultural costarricense" (Monge, 2012: 23).

Esta investigación evaluará el panorama del ambiente artístico costarricense descrito por Yolanda Oreamuno en tres de sus publicaciones presentes en Repertorio Americano. El tema de esta propuesta nace a partir de la creación de un minisitio en Internet realizado para conmemorar el centenario del nacimiento de Oreamuno, por parte de la Biblioteca Digital de la Facultad de Filosofía y Letras, Scriptorium. Este minisitio es producto de una investigación que dejó como productos: un estudio biográfico sobre la autora, una cronología, una recopilación de sus fotografías, su obra literaria publicada en $R e$ pertorio, así como comentarios y crítica escrita sobre ella.

Yolanda inicia su escritura en Repertorio con su afamado artículo: "Medios que usted sugiere al colegio para librar a la mujer costarricense de la frivolidad ambiente", en 1933. El origen de este texto tiene que ver con su participación en un concurso de ensayo del Colegio Superior de Señoritas. Su última obra aparecida en Repertorio fue "Un regalo", en 1948. Es decir, su periodo de producción en el periódico fue de aproximadamente 10 años, aunque todo su periodo de escritura se estableció en veinte años aproximadamente (Monge, 2016: s.p.).

Los textos publicados en este segmento cultural inician con el ensayo y pasan por el cuento, como en el caso de "La lagartija de la panza blanca" (1936) o "Misa de ocho" (1937); otros han sido clasificados como narrativa lírica, por mencionar algunos: "Vela urbana" (1937), "La vuelta a los lugares comunes" (1939) y “Apología del limón dulce" (1944).

Ensayos como "El último Max Jiménez ante la indiferencia nacional" (1939), "Protesta contra el folclore" (1943), y “Max Jiménez y los que están” (1947) definen el ambiente costarricense de la época, la producción artística, el carácter "tico" frente al arte y el papel del artista en el país. En todos ellos se perfila la visión crítica de la autora y se define su carácter mordaz. A estas tres obras les daremos énfasis en este estudio.

Debido a estas dos décadas de producción literaria (años 30 a 40), Oreamuno es clasificada dentro de la generación del desencanto o del 40. En este grupo de escritores se inscriben Carlos Luis Fallas, Adolfo Herrera García, Fabián Dobles, Joaquín

1 Conocido como “QQué hora es?” por haber aparecido en la sección de Repertorio que llevaba este nombre. 
Gutiérrez, Francisco Amighetti, Arturo Echeverría Loría, Fernando Centeno Güell, Eunice Odio, Rodrigo Facio y Luis Barahona (Ovares et al; 1993: 224). Estos escritores tuvieron cualidades en común que los identificaron como generación. Entre estas, muchos de ellos escribieron en el Repertorio (aunque se consideran posteriores a la generación del Repertorio), fundado en 1919, hecho que logra "la difusión de sus obras en el extranjero" (Quesada, 2002:158). Asimismo, todos proyectaron en su arte la ruptura hacia una visión idílica sobre la sociedad costarricense, la cuidad o el costarricense de carácter pacífico. En sus obras literarias, los problemas psicológicos en sus personajes se hacen presentes, así como los vicios de las diferentes clases sociales. Estos autores trazan un proyecto ideológico cuyo objetivo es la construcción sincera de Costa Rica, aunque esto significó, en muchos casos, representar la degradación general del país.

La generación tuvo como insumo la obra de Max Jiménez o de José Marín Cañas, quienes hicieron los "primeros esfuerzos por incorporar los experimentos de la modernidad en la narrativa costarricense" (Quesada, 2002: 165). Pero, desde la perspectiva de Carlos Francisco Monge, en El vanguardismo literario costarricense, aún se confrontaban con resabios de un discurso fundacional o nacionalista pero debilitado desde 1920 , por lo que se vieron obligados a experimentar y desarrollar estilos iconoclastas. A continuación, una breve descripción del contexto artístico:

la década de 1920 presenció el debilitamiento del modelo liberal oligárquico... se incrementó una ideología reivindicativa entre trabajadores urbanos; se ponen en entredicho los viejos liderazgos; entre la clase media surgieron estudiantes y grupos intelectuales con posiciones beligerantes... La pequeña ciudad de San José crece y, pese a todo, también se moderniza. Los ocho años entre la aparición del Partido Reformista, en 1923, y la fundación en 1931 del Partido Comunista, marcaron la transición entre dos épocas, dos ideas de nación y dos modos de ejercer la literatura y el arte. La avalancha de "un arte moderno" integrado por artistas europeos y americanos hicieron que los costarricenses entraran en contacto con ellos. (Monge, 2005: 40)

Oreamuno, como caso específico, vive en un periodo de transición hacia nuevas construcciones artísticas. Su obra literaria no escapa de exteriorizar esos procesos de cambio de la década de los 30 entre las manifestaciones de un realismo costumbrista y las modernistas. Su obra crítica como literaria opta por una tendencia renovadora y expone las problemáticas costarricenses. Por lo anterior, en La casa paterna su ensayística se define de este modo:

Los ensayos de Yolanda Oreamuno se distancian de la visión idílica del campesino costarricense e ironiza sobre los estereotipos nacionales. $\mathrm{Su}$ reclamo de una literatura que se ocupe de lo urbano y se aleje de los mitos revela una posición fuertemente crítica ante la cultura nacional. (Ovares et al; 1993: 264) 
La cita anterior atañe a los ensayos de Oreamuno publicados en Repertorio, donde la autora describe un espacio carente de apertura hacia la experimentación de nuevas tendencias artísticas. Costa Rica es para ella un espacio que impide el crecimiento artístico debido a sus ataduras con un modelo consolidado: el costumbrismo, cuyo objetivo es establecer una imagen idílica de nación (Ovares et al; 1993: 223): además, "su enfoque de la vida popular parte de cierta idealización de las costumbres y tradiciones patriarcales y campesinas, en que la tragedia, los vicios e injusticias sociales y morales, se diluyen, absorbidos por el giro pintoresco o la anécdota divertida" (Quesada, 1983: 67). En el caso de "Protesta contra el folclore", la escritora plantea su disconformidad con las manifestaciones costumbristas o folclóricas cuando indica lo siguiente-una de las citas más mencionadas sobre la autora-:

Literariamente, confieso por $\mathrm{mi}$ parte que estoy HARTA, así, con mayúsculas, de folclore. Desde este rincón de América puedo decir que conozco bastante bien la vida agraria y costumbrista de casi todos los países vecinos, y en cambio, sé poco de sus demás palpitantes problemas. Los trucos colorísticos de esa clase de arte están agotados, el estremecimiento estético que antes producían ya no se produce, la escena se repite con embrutecedora sincronización, y la emoción huye ante el cansancio inevitable de lo visto $\mathrm{y}$ vuelto a ver. (Oreamuno, 1943: 2)

Esta perspectiva en contra del arte realista costumbrista será el eje temático en los ensayos. En este mismo escrito prosigue de este modo: "yo estimo que el clímax de saturación ha llegado y acuso a la literatura folclorista de unilateralidad. Considero que más folclore, visto como única corriente artística posible en América, significa decadentismo"(Oreamuno, 1943: 1). Yolanda es consciente de la necesidad de cambio y apertura a nuevas corrientes que ya en Latinoamérica llevan tiempo gestándose, como es el caso de las vanguardias latinoamericanas, que ya en los treintas, según Jorge Schwartz, estaban viendo su fin con el último de los manifiestos en Nicaragua, en 1931 (Schwartz, 2000: 38). Los movimientos de ruptura y experimentación en las letras no podían pasar inadvertidas en Costa Rica. Repertorio publicó numerosos artículos relacionados con las vanguardias (tanto europeas como latinoamericanas), por mencionar dos casos, en 1930 un artículo titulado "5 poetas brasileros de vanguardia" y en 1940 otro llamado "Rápido comentario sobre la poesía de vanguardia".

Oreamuno emplea en dos de sus artículos, "El último Max Jiménez ante la indiferencia nacional" y "Max Jiménez y los que están," la figura de este artista para detallar el asfixiante ambiente vivido a quienes proponían distinciones al modelo normativo del momento. Artistas costarricenses como Jiménez, Francisco Amighetti y José Marín Cañas, entre otros, han sido clasificados recientemente como vanguardistas por la crítica. En el caso de Jiménez, en su recorrido por países como Francia y Cuba, no solo apreció tendencias vanguardistas en el arte sino que también fue parte de ellas, al "romper con la trivialidad o la rutina... y arrostrar el orden establecido" (Monge, 2005: 34). 
En "El último Max Jiménez ante la indiferencia nacional" expone su queja sobre la poca recepción de la pintura del pintor por parte del público; además, deja en claro que el deseo de su publicación no consiste en el simple elogio de la obra sino combatir la tibieza del costarricense, ya que la obra de Jiménez careció de crítica en los medios de comunicación, por lo que escribe:

En Costa Rica es necesario morirse para recoger el reconocimiento póstumo de este pueblo desdeñoso y pasivo. $\mathrm{O}$, caso de tenerse mucha impaciencia en la cosecha, basta convertirse en personificación de la academia fósil de otro tiempo, sin renovación vital de ninguna índole, para que el vaho tibio del agradecimiento nacional cubra como un incienso el pedestal de la viviente estatua consagrada. (1939: 3)

Vemos, con esta cita, el planteamiento de otras problemáticas: la visión del objeto como artístico solo bajo el amparo de la academia, la carencia de impulsos renovadores dentro del arte y la imposibilidad de sensibilidad del costarricense.

Otro detalle que se debe de valorizar en la propuesta de Oreamuno es la importancia que le da a la objetividad en la recepción del arte, obviando percepciones ligadas a relaciones afectuosas (ella indica que comparte correspondencia con el autor). Lo que trasciende al momento de generar crítica es el esfuerzo, la entrega del artista, quien en el proceso creativo cuenta con un propósito:

Sus manos que se endurecen luchando con la piedra y que empiezan a adquirir sabiduría maestra, ante ablandarse de nuevo para coger el pincel; la mente orientada en proa al sendero poético desfallece dentro de un cuarto oscuro donde Max, escabu1lizo, revela mecánicamente negativos fotográficos. Cada nuevo rumbo significa un paralelo abandono de la línea en que ya su mente, su habilidad y su sensibilidad se habían enfocado. ¿Es esto o no susceptible de modificar la intensidad constructiva de un artista? Yo estimo que sí lo es. (1939: 1)

Oreamuno demuestra en este fragmento, además de su habilidad en la escritura, su exigencia de crítica mediante el debate y los cuestionamientos.

El análisis continúa en "Max Jiménez y los que están," en donde denuncia la carencia de conocimiento y reflexión profunda del arte debido a esta misma subjetividad; propone un estudio no tergiversado de las obras posiblemente por visiones preconcebidas de lo "bello" debido a modelos tradicionalistas:

cuando por casualidad aludían directamente a la obra, siempre dijeron " $\mathrm{El}$ Jaúl no lo he leído, pero dicen que es muy vulgar"; "Revenar, Sonaja y Gleba no lo conozco"; "sus cuadros son espantosos, jesas mujeres con las cabezas pequeñas y los brazos enormes! ¡Son horribles!’. ¡Pues es claro, queridos paisanos, que son horribles! ¡No han hecho ustedes ningún descubrimiento trascendental! Sólo se les olvidó ver que el mensaje pictórico, el camino nuevo, la enseñanza del maestro, NO SIEMPRE ESTÁN EN LA BELLEZA. (1947: 3) 
Oreamuno logra percibir, a través de una visión crítica, la intencionalidad de la obra de Jiménez, desde un nivel connotativo, con lo que permite que esta supere la muerte del autor; de este modo, adquiere una visión objetiva, como lo expone en "Max Jiménez y los que están” (1947): "Yo insisto, Max Jiménez, como persona, no importa para nuestra cultura, importa solo para sus amigos, y somos bien pocos" (Oreamuno 4). Esta ideología muestra su poder de análisis, similar a los planteamientos propuestos años después por Roland Barthes o Michel Foucault ${ }^{2}$, al referirse a una crítica alejada de la vida del autor, porque esta muere al mismo momento de la creación, porque lo que interesa para lo social y literario es la creación y su trascendencia histórica.

La autora recomienda dar reconocimiento a lo que otros medios obvian como parte de la creación artística del país porque resulta novedoso o diferente. Con ello deja en claro que está al tanto del cambio que se ha gestado internacionalmente. En este mismo artículo, compara la creación literaria de Max Jiménez con obras cumbres de la literatura latinoamericana, como Don Segundo Sombra (1926) o La vorágine(1924), por ser un referente a una obra moderna y generadora de cambio para las letras con la creación de El Jaúl o Revenar. Autores como Rómulo Gallegos o José Eustasio Rivera crearon sus obras mundonovistas debido a que se atrevieron a traspasar la raya de lo admitido y rellenar una carencia de su momento, como lo indica Oreamuno: "La obra de arte, con errores o sin ellos, se produce porque el

2 Barthes con "La muerte del autor" (1968) y Michel Foucault con “¿Qué es un autor?” (1969). autor logró dar un nuevo mensaje, interpretar un momento trascendente, pintar la esencia de un pueblo, abrir camino, responder a una necesidad vital" (Oreamuno, 1947: 1). Desde esta perspectiva, Oreamuno fue visionaria sobre la trascendencia histórica de Jiménez, ya que tuvieron que pasar muchos años para que su obra adquiriera validez para la crítica costarricense.

Ante el tenue panorama hacia posibilidades artísticas transgresoras, descrito por la autora, el espacio a donde se relega al artista es el exilio: "Max Jiménez hace bien en ir a buscar a otros sitios, gente a quien mostrarles su dación artística, ya que la mayoría de los nuestros, por inamovible indiferencia nacional o, por las mediocres rencillas de pantano que infestan el ambiente, consideran desvalorizada su granítica dignidad en darse por simplemente enterados" (Oreamuno, 1939: 1). Con un ejemplo individual del autor se manifiesta el ambiente general vivido por los artistas de su época: rencillas internas, mediocridad y celos.

Comprendemos que esta opción de autoexilio es la avalada por la escritora ya que ella eligió este mismo camino, cuando pasó gran parte de su vida entre Guatemala y México (Vallbona, 1972:90). Además, este sentimiento de poco apoyo había sido expuesto por otros artistas que se consideraron incomprendidos como Chavela $\operatorname{Vargas}^{3}$ o Eunice Odio ${ }^{4}$. El mismo Max Jiménez declara a Joaquín García Monge el panorama devastador sobre su

3 Expone en sus biografías que Costa Rica no la apoyó en su carrera como cantante por su orientación sexual. Se exilia en México en 1934 o 1936, las biografías no coinciden.

4 Se nacionaliza mexicana en 1972 (Chen y Vallbona: 2001). 
experiencia, confirmando los comentarios de Oreamuno: "Yo soy testigo del más absoluto de los abandonos, que es probablemente nuestra cualidad característica, el abandono movido por el aislamiento lastimoso" (Quesada, 2002: 162). A esta visión desilusionada se le suman comentarios negativos sobre el país de Emilia Prieto, Carmen Lyra, Eduardo Uribe o Mario Sancho (Quesada, 2002: 163).

Luego de estas visiones expuestas por Oreamuno, observamos que Repertorio recopila la discusión de la escritora sobre la transición entre nuevos pensamientos concernientes en el arte. Ella defiende la necesidad de un arte novedoso a pesar de la preferencia por lo tradicional en el ambiente del país. Además de exteriorizarlo en la crítica, lo pondrá en práctica en sus textos, como sucede en La ruta de su evasión (1948). Repertorio se consolida como un espacio abierto a la discusión, al debate que intenta librar al costarricense del conformismo y la indiferencia frente a las diferentes propuestas que se estaban gestando.

Por su parte, Oreamuno construye un panorama cultural pesimista en el cual se presenta la desaprobación con modelos artísticos costarricenses por el seguimiento de modelos tradicionalistas y, lo que es peor, por el desconocimiento de nuevas tendencias o la insensibilidad ante la obra desconocida.

Oreamuno perfila un espacio necesitado de crítica seria, objetiva y aislada de los cerrados cánones impuestos por la academia. Además de carente de criticidad y permeado por la apatía y la subjetividad en el tratamiento de obras de personalidades apenas conocidas por el público general, características que impiden al artista crecer y, por el contrario, lo limita y lo hace huir fuera de sus fronteras.

La paradoja está en esa percepción sobre el ambiente costarricense y ella como creadora dentro del ambiente negativo que perfila (al menos en los primeros años de la década de los treintas). Ella se consolida y prospera, no solamente como escritora de calidad sino como lectora comprometida, estudiosa de la literatura latinoamericana y crítica de esta, y sobresale frente al panorama retrógrado que señala en sus textos.

Oreamuno entiende que la obra trasciende a su creador o la aceptación de la academia o la intelectualidad; la obra de calidad permanece a través del tiempo y obvia el mal trato que pudo recibir en su momento de creación. El costarricense, entonces, ligado a sentimientos mezquinos, procura el reconocimiento post mortem de sus artistas.

\section{Referencias bibliográficas}

Chen, Jorge y Rima de Vallbona. La palabra innumerable: Eunice Odio ante la crítica. San José: Editorial de la Universidad de Costa Rica, 2001.

Cortina, María y Chavela Vargas. Las verdades sobre Chavela. México: Editorial Océano, 2009.

Monge, Carlos Francisco. El vanguardismo literario en Costa Rica. Heredia: Editorial de la Universidad Nacional, 2005

Monge, Carlos Francisco. "Los territorios literarios de Yolanda Oreamuno". Conferencia presentada en la actividad de homenaje y conmemoración del centenario de Yolanda 
Oreamuno Universidad Nacional. Heredia: Universidad Nacional, 13 de abril de 2016.

Oreamuno, Yolanda. "El último Max Jiménez ante la indiferencia nacional". Repertorio americano, 26 agosto 1939: 281- 283.

. "Protesta contra el folclore". Repertorio americano. 13 marzo 1943: 84.

. "Max Jiménez y los que están". Repertorio americano, 16 agosto 1947: 53.

Ovares, Flora, Margarita Rojas, Carlos Santander y María Elena Carballo. $\mathrm{La}$ casa paterna. San José: Editorial de la Universidad de Costa Rica, 1993.
Quesada, Álvaro. "Actitud crítica en el costumbrismo costarricense." Revista de Filología y Lingüística de la Universidad de Costa Rica 9.1: 67-74. . Uno y los otros. San José: Editorial de la Universidad de Costa Rica, 1998

Vallbona, Rima de. Yolanda Oreamuno. San José: Ministerio de Cultura, Juventud y Deportes, 1972.

Schwartz, Jorge. Las vanguardias latinoamericanas. México: Fondo de Cultura Económico,. 2000. 


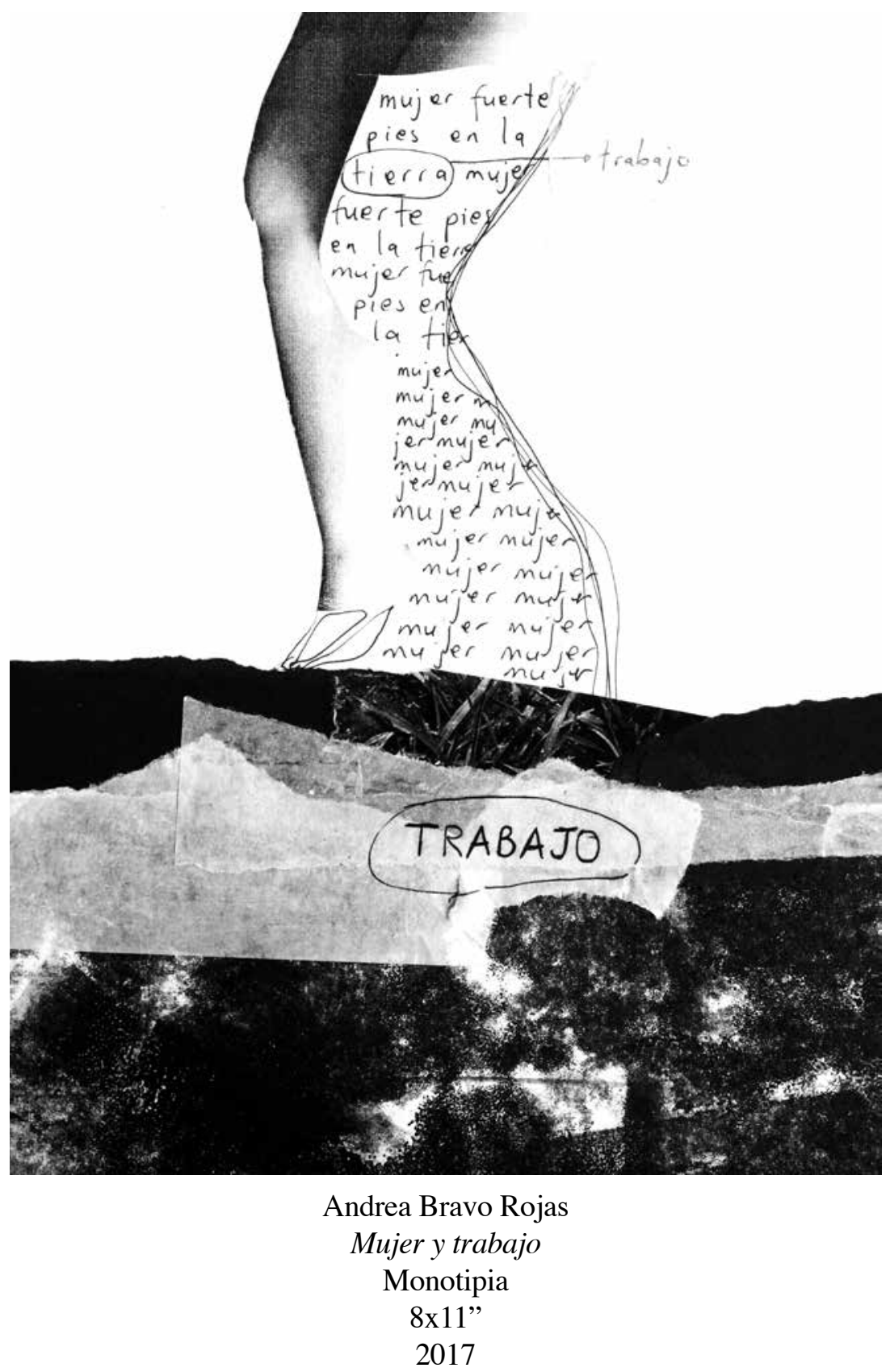

